M. В. Золхоева. Угроза глобального потепления: нравственное измерение (взгляд с позиции философии интегрализма)

Научная статья

УДК 504.7:1

DOI: 10.18101/1994-0866-2021-4-3-10

\title{
УГРОЗА ГЛОБАЛЬНОГО ПОТЕПЛЕНИЯ: НРАВСТВЕННОЕ ИЗМЕРЕНИЕ (ВЗГЛЯД С ПОЗИЦИИ ФИЛОСОФИИ ИНТЕГРАЛИЗМА)
}

\author{
(C) Золхоева Мария Валентиновна \\ доктор философских наук, доцент, \\ заведующая кафедрой философии, \\ Бурятский государственный университет имени Доржи Банзарова \\ Россия, 670000, г. Улан-Удэ, ул. Смолина, 24a \\ badmaeva_maria@mail.ru
}

Аннотация. В статье рассмотрены некоторые результаты осмысления проблемы глобального потепления, находящейся в центре внимания специалистов самых разных областей научного знания, общественности в целом, в течение последних десятилетий. Указанная проблема стала целью работы нескольких международных саммитов, выработавших ряд соглашений, направленных на защиту окружающей среды от постоянно возрастающей антропогенной нагрузки. Отмечено, что поиск решения проблемы глобального изменения климата осуществляется, главным образом, в плоскости политических решений и договоренностей. Но, по мнению автора работы, для успешного обсуждения и поиска адекватных способов решения рассматриваемой задачи, равно как и других не менее значимых глобальных проблем, необходимо обращение к сущности человека, ее важнейшей нравственной составляющей. Без осознания этой родовой особенности человека любое решение общих для человечества проблем представляется неэффективным и невозможным. Автор также отмечает близость представленной позиции воззрениям выдающегося русско-американского мыслителя, ученого П. А. Сорокина, создателя интегральной концепции общества и человека.

Ключевые слова: общество, человек, нравственность, глобальные изменения климата, угроза глобального потепления, ООН, Рамочная конвенция ООН, Киотский протокол, Парижское соглашение, 26-я конференция ООН по изменению климата, П. А. Сорокин, интегрализм.

\section{Для цитирования}

Золхоева М. В. Угроза глобального потепления: нравственное измерение (взгляд с позиции философии интегрализма) // Вестник Бурятского государственного университета. Философия. 2021. Вып. 4. С. 3-10.

Современный этап в развитии человеческой цивилизации можно смело назвать эпохой глобальных проблем. Одной из них является угроза глобального потепления, глобального изменения климата.

Именно климатические изменения, а также все возрастающая антропогенная нагрузка на окружающую среду, по мнению специалистов, становятся причиной многочисленных наводнений, пожаров, крупных аварий, природных и техногенных катастроф, все чаще сотрясающих земной шар в самых разных его регионах последние десятилетия [6, с. 40].

Потому не случайно, что экологические проблемы давно стали неизменным пунктом повестки дня в политических программах лидеров национальных госу- 
дарств, привлекая внимание не только экоактивистов, но и абсолютного большинства обычных граждан, всерьез обеспокоенных перспективами человечества, оказавшегося в столь напряженных отношениях с собственной средой обитания. Один за другим средства массовой информации освещают международные встречи на самом высоком уровне, основной задачей которых является попытка сохранить хрупкий баланс человека и природы, защитить и сохранить Землю для будущих поколений людей.

Отметим в связи с вышесказанным, прежде всего, конференции ООН, обсуждавшие разнообразные подходы к пониманию и решению глобальных проблем экологии, состоявшиеся в 1972 г. в Стокгольме и в 1992 г. в Рио-де-Жанейро. На последнем из указанных мероприятий было составлено первое международное соглашение о противодействии глобальным климатическим трансформациям (Рамочная конвенция ООН об изменении климата).

Необходимо также упомянуть принятое в 1997 г. дополнение к конвенции, направленное на сокращение парниковых выбросов (Киотский протокол) и так называемое Парижское соглашение 2015 г., завершившееся созданием еще одного договора, устанавливающего меры, направленные на уменьшение содержания углекислого газа в атмосфере Земли. Его авторы и разработчики стремились создать документ, который не только перечислял возможные способы достижения цели, но и гарантировал их обязательное исполнение, тем самым напрямую оказывая содействие уже ведущейся борьбе против негативного для человечества ухудшения климатических условий и за столь необходимый переход к «зеленой» экономике будущего, не использующей или ограниченно использующей прежние производственные технологии, существующие еще со времен индустриализации. Уже к 2050 г. более 200 государств ставили перед собой цель достигнуть «нулевого углеродного следа».

Но, несмотря на значительные средства, потраченные на охрану природы, борьбу с непрекращающимися природными и рукотоворными катаклизмами, развитие и разработку новых, дружественных «зеленой» экономике технологий, ситуация не только не улучшилась и не стабилизировалась, а, напротив, продолжает год от года ухудшаться, лишая человечество остатков надежды на счастливое разрешение проблемы. Все принятые документальные соглашения так и не привели к заметному и значимому позитивному изменению, а внедрение экологических технологий все еще находится в зачаточном состоянии. К тому же переоборудование предприятий, работающих на углеродном топливе, на нефти и газе в сложившейся финансовой ситуации, когда мир вновь готовится к очередному кризису, представляется крайне затратным и практически неосуществимым .

Возможные итоги проходящей в Глазго в ноябре текущего года 26-й всемирной конференции ООН по климату специалисты еще до начала мероприятия оценивали крайне скептически и осторожно. С одной стороны, участники конференции, как свидетельствует проект итогового документа, подтвердили «...поставленные в Париже в 2015 г. цели по ограничению потепления до 2 гра- 
М. В. Золхоева. Угроза глобального потепления: нравственное измерение (взгляд с позиции философии интегрализма)

дусов по Цельсию (3,6 градуса по Фаренгейту) с доиндустриальных времен» ${ }^{1}$ и даже поставили перед собой задачу сдерживать потепление до 1,5 градуса по Цельсию.

Но, с другой стороны, неразрешимой остается финансовая проблема. Еще в 2009 г. развитые страны взяли на себя обязательства выделять не менее 100 миллиардов долларов в год на проекты в области совершенствования и перестройки промышленных предприятий в странах с менее развитой экономикой. Но обещание так и осталось на бумаге. Вот и сегодня в проекте итогового документа конференции в Глазго уже «..."с сожалением" признается, что богатые страны не смогли выполнить свое обещание предоставлять к 2020 г. финансовую помощь в размере $\$ 100$ миллиардов в год, чтобы помочь бедным странам, пострадавшим в результате глобального потепления» ${ }^{2}$.

Действительно, экономическая помощь в таком объеме сегодня требует мобилизации огромных ресурсов и выглядит трудно выполнимой даже для первой экономики мира. Не случаен и показателен выход из числа членов Парижского соглашения США, имевший место в недавнем прошлом, в период президентства Д. Трампа. В настоящее время США под руководством Д. Байдена вновь являются участниками международного договора и демонстрируют готовность к дальнейшим действиям в борьбе с климатическими изменениями.

Поиски решения проблемы человечество ведет в самых разнообразных направлениях и, прежде всего, в сфере новых технологий и научных открытий, призванных нивелировать уже существующий ущерб и предотвратить возможные последствия глобального потепления в будущем. Чрезвычайно важной в данном случае представляется объективная оценка и научное прогнозирование исследуемых явлений. Специалисты из разных областей научного знания регулярно проводят необходимые эмпирические исследования, строят математические модели, пытаются оценить масштабы трансформации привычного нам мира в случае неблагоприятного развития событий.

Так, И. А. Макаров, оценивая экономические последствия глобального изменения климата, выделяет следующие наиболее существенные и негативно влияющие на жизнь социума явления: снижение урожайности важнейших сельскохозяйственных культур, разрушение значительных по площади прибрежных территорий вследствие процессов глобального потепления, увеличение числа и масштабов природных катаклизмов, подъем заболеваемости и смертности, возникающий из-за неподготовленности организма человека к резким и непривычным погодным, климатическим изменениям, дефицит пресной воды, разрушение привычной среды обитания многих веками существующих экосистем [5, с. 515].

Особую значимость проблемы глобального потепления доказывает и тот факт, что в 2021 г. Нобелевскую премию по физике получили трое ученых, среди них - Сюкуро Манабе из США. Манабе был награжден за работы, проведенные им еще в 1960-х гг., в которых ученый выявил механизм взаимосвязи между повышением уровня углекислого газа в атмосфере и повышением температуры на

1 URL: https://rossaprimavera.ru/news/803b73a8?utm_source=yxnews\&utm_medium= desktop\&nw=1636542039000 (дата обращения: 10.11.2021). Текст: электронный.

2 Там же. 
поверхности Земли. Манабе стал создателем первой модели глобального климата, ему удалось перевести набор уравнений, отражающих физические законы, в практическое русло - получить его численные решения. Эта работа и многие последовавшие вслед за ней исследования позволили современной науке о климате, климатологии создавать обоснованные прогнозы изменений климата на нашей планете на ближайшие десятилетия. От точности таких прогнозов будет в значительной степени зависеть развитие всей человеческой цивилизации, всех главных составляющих жизни социума: экономики, политики, социальной и духовной сферы. Потому важность и значимость подобной информации невозможно переоценить.

Сам факт вручения Нобелевской премии за изучение климатических изменений говорит о высочайшем уровне актуальности проблем экологии, климатических изменений, глобального потепления и значимости науки, научных исследований. Безусловно, без передовых исследований в области науки справиться с решением столь сложной задачи невозможно. Но достаточно ли одной науки? Означает ли это, что людям, далеким от науки, научного поиска, нужно просто подождать, когда ученые найдут. Ответ, придумают «волшебную таблетку» о глобального потепления, и все встанет на свои места? Очевидно, нет. Но что может сделать обычный человек для решения проблемы глобального потепления? Если попытаться обобщить разнообразные рекомендации, то получим следующий перечень:

1. «Человеку рекомендуется для начала посадить на своем участке как можно больше деревьев или следить за ростом старых.

2. Использовать как можно больше энергосберегающих ламп, батарей и других источников энергии.

3. Стараться производить как можно меньше отходов и чаще использовать перерабатываемое сырье.

4. Доносить проблему глобального потепления до большого количества людей: своих близких, друзей и знакомых» ${ }^{1}$.

Являются ли предложенные меры не только необходимыми, но и достаточными?

На наш взгляд, для успешного обсуждения, решения глобальных проблем и, в частности, проблемы глобального изменения климата необходимо, прежде всего, переосмысление человеком самого себя, своей природы, собственной сущности. Мы привыкли, что проблемы человека является древнейшей философской проблемой и не существует единственно верного ответа на вопрос о сущности человека. Все согласны с тезисом о двойственной, биосоциальной природе человека, его неразрывной связи с миром природы и способности жить среди себе подобных. Первым ответом на вопрос об отличии человека от не-человека, как правило, считают его разумность, наделенность сознанием. Однако уже в античности сформировалась точка зрения, согласной которой разумность человека отождествлялась с его нравственностью, способностью различать добро и зло и делать выбор в пользу добра. Именно так, в частности понимал природу человека Сократ.

\footnotetext{
${ }^{1}$ URL: https://tion.ru/blog/globalnoe-poteplenie/ (дата обращения: 10.11.2021).
} 
М. В. Золхоева. Угроза глобального потепления: нравственное измерение (взгляд с позиции философии интегрализма)

В современном мире разговоры о нравственности давно стали уделом образовательных программ и родительских наставлений. Мы стали воспринимать эту сущностную особенность человека как некую данность, присутствующую необходимым образом в жизни любого совершеннолетнего человека, и предоставили возможность дискутировать о ней специалистам в области этики, социальной философии, психологии, других гуманитарных и социальных дисциплин.

Однако нравственность - это не просто одна из особенностей человеческого индивида. Это именно его сущностная черта, делающая человека человеком и отличающая его от всех других живых существ. Данный тезис был совершенно очевиден для создателя интегральной концепции мира и человека, выдающегося русско-американского мыслителя, философа, социолога Питирима Александровича Сорокина.

Сорокин в своих произведениях разных лет особое внимание уделял обсуждению именно этической проблематики. Нравственные ориентиры, идеалы и ценности всегда были в центре внимания исследователя. Уже в ранних социологических работах Сорокин, придерживаясь позитивистских установок в своем научном исследовании, однако указывал, что «предмет социологии и социальных наук в целом отличается от предмета физических и биологических наук», так как человек находится под воздействием надорганической среды, в которой он рождается и воспитывается. Поэтому, в частности, его научные взгляды никогда не были односторонними, не ограничивались той или иной стороной знания, что неизбежно вело его к убеждению в необходимости создать синтетическое учение с максимальным включением в него данных различных наук. Он писал, что различные исследователи при изучении общественной жизни «берут за исходное разные знания. Конечная же цель социолога заключается в комбинировании их таким образом, чтобы в итоге получился ряд теорем о взаимной связи отдельных элементов общественной жизни» [1, с. 49]. В «Социальной и культурной динамике» он предпринял попытку создать такое синтетическое учение, где через изменения в крупнейших культурных системах, таких как наука, политика, мораль и т. д., объяснялись масштабные исторические процессы, претерпеваемые человечеством. Но он не удовлетворился лишь созданием историософской теории. Стремление непосредственно участвовать в преобразующей практической деятельности всегда было очень сильно в Сорокине. Как известно, ученый был уверен в том, что любой из членов общества может содействовать менее болезненному и более быстрому выходу социальной системы из любой кризисной ситуации посредством проявления созидательной энергии неэгоистической, альтруистической любви. Он даже стал основателем Гарвардского исследовательского центра по проблемам творческого альтруизма. Работа этого центра осуществлялась в рамках решения главной задачи - сделать человека лучше. Центр разрабатывал пути развития сострадания, симпатии, любви и соучастия в любых общественных начинаниях. Центр, в частности, проводил исследования среди меннонитов и гуттеритов, которые, по мнению Сорокина, являются исключительно альтруистическими сообществами. Полученные результаты и выводы позволили Сорокину сформулировать собственное учение о роли и значении творческой неэгоистической любви, способной стать средством духовного преображения человечества, преодоления им любых социальных проблем и конфликтов. 
Человек, считает Сорокин, пройдя сквозь горнило кризиса, явно осознает, что единственным условием его выживания и процветания является политика реализации моральных ценностей любви, дружбы, взаимопомощи и сострадания. Прежняя же политика, диктуемая неограниченным эгоизмом, ненавистью, обманом и лицемерием, - прямой путь к гибели. Любовь, а не ненависть, является созидающим началом в истории. Значение ее гораздо больше, чем значение биологической борьбы за существование. Лишь милосердие, дружелюбие, высокая мораль в сочетании с мудростью и красотой способны объединить человечество, преодолеть все существующие противоречия и вывести его на новый, более совершенный этап развития.

Сорокинская концепция нравственности не предполагает коренного изменения всего населения, не предполагает отказа от несовместимых с идеями добра и альтруизма ценностей и поведенческих паттернов каждым представителем человеческого общества. Сорокин, главным образом, обращается к тем, кто, разделяя высокие нравственные идеалы, в то же время не находит в себе достаточно мотивации и сил для реализации этих теоретических представлений в практике социальной деятельности. Эти люди, составляющие абсолютное большинство в любом обществе, нравственно нейтральные, пассивные, не стремящиеся к отстаиванию имеющихся у них ценностных представлений, склонные всегда оставаться «в тени», предоставляя другим, более смелым и активным членам сообщества совершать тот или иной выбор, способны стать главной движущей силой позитивных нравственных изменений, помогая человечеству в целом безопасно и успешно совершить переход от чувственного к интегральному социокультурному порядку.

Другими словами, именно мораль в теоретической концепции Сорокина становится ключом к выживанию, сохранению человечества как вида, главным условием позитивных социокультурных преобразований, средством преодоления возникающих в обществе проблем и препятствий.

В настоящее время в контексте обсуждаемой в нашей статье проблемы глобальных климатических изменений и ее влияния на судьбу и будущее человечества в целом позиция Сорокина звучит как никогда актуально. Нравственная сущность человека, его способность не только различать между добром и злом, но и действовать в соответствии с моральным законом, по нашему мнению, есть залог правильной постановки и поиска решения всего обширного комплекса глобальных проблем. У современного человека уже не осталось времени выбирать между материальной выгодой и нравственным долгом перед собой и всем остальным человечеством. У него нет также возможности переложить бремя ответственности за решение указанной проблемы на других людей. Сегодня, как никогда ранее, человечество стало вынужденно единым организмом. В этих условиях осознание себя подлинно нравственным существом является необходимым условием принятия верных решений, способных предотвратить климатический коллапс и сохранить шансы человечества на дальнейшую жизнь.

Литература

1. Алексеев В. А., Маслин М. А. Русская социальная философия конца ХІХ начала XX века. Москва : Исслед. центр по пробл. управления качеством подгот. специалистов, 1992. 192 с. Текст: непосредственный. 
M. В. Золхоева. Угроза глобального потепления: нравственное измерение (взгляд с позиции философии интегрализма)

2. Бондаренко Л. В., Маслова О. В., Белкина А. В., Сухарева К. В Глобальное изменение климата и его последствия // Вестник РЭУ им. Г. В. Плеханова. 2018. № 2(98). С. 84-93. Текст: непосредственный.

3. Браун Л. Как избежать климатических катастроф?: План Б 4.0: спасение цивилизации. Москва : Эксмо : Коммерсанть, 2010. 413 с. Текст: непосредственный.

4. Джеффрис, В. Интегрализм Сорокина: новая общественная наука и реконструкция человечества // СОЦИС. 1999. № 11. С. 13-17. Текст: непосредственный.

5. Макаров И. А. Глобальное изменение климата как вызов мировой экономике и экономической науке // Экономический журнал ВШЭ. 2013. № 3. С. 479-494. Текст: непосредственный.

6. Основы защиты населения и территорий в кризисных ситуациях / под общей редакцией Ю. Л. Воробьева; МЧС России. Москва: Деловой экспресс, 2006. 539 с. Текст: непосредственный.

7. Русакова Ю. А. Климатическая политика Российской Федерации и решение проблем изменения глобального климата // Вестник МГИМО - Университета. 2015. № 1. С. 66-72. Текст: непосредственный.

8. Сорокин П. А. Главные тенденции нашего времени. Москва: Наука, 1997. 351 с. Текст: непосредственный.

9. Сорокин П. А. Таинственная энергия любви // СОЦИС. 1991. № 8-9. С. 121-137. Текст: непосредственный.

10. Sorokin P. A. Man And Society In Calamity. The effects of war, revolution, famine, pestilence upon human mind, behavioral, social organization and cultural life. N. Y.: E. P. Dutton \& Co. Inc., 1942. 352 р. Текст: непосредственный.

11. Sorokin P. A, Lunden W. Power and Morality: Who Shall Guard the Guardians? Boston, 1959. 204 p.

Статья поступила в редакциюю 11.11.2021; одобрена после рецензирования 15.11.2021; принята к публикации 15.11.2021.

\title{
THREAT OF GLOBAL WARMING: A MORAL DIMENSION (FROM THE PERSPECTIVE OF THE PHILOSOPHY OF INTEGRALISM)
}

\author{
Mariya V. Zolkhoeva \\ Dr. Sci. (Philos.), A/Prof., \\ Head of Philosophy Department, \\ Dorzhi Banzarov Buryat State University \\ 24a Smolina St., Ulan-Ude 670000, Russia \\ badmaeva_maria@mail.ru
}

Abstract. The article discusses the comprehension of the problem of global warming, which is in the center of attention of specialists in various fields of scientific knowledge, and society as a whole over the past decades. This problem became the goal of the work of several international summits, in this regard they developed a number of agreements aimed at protecting the environment from the constantly increasing anthropogenic load. It is noted that the search for a solution to the problem of global climate change is carried out mainly through the lens of political decisions and agreements. But we believe that it is necessary to turn to the human nature, his most important moral component for a successful search for adequate ways to solve the problem under consideration, as well as other equally significant global problems. Without understanding this generic aspect of a human, any solution to problems common to humanity seems to be ineffective and impossible. We also emphasize the like- 
mindedness of the views of the outstanding Russian-American thinker, scientist P. A. Sorokin, the author of the concept of the society and human integrity.

Keywords: society, human, morality, global climate change, threat of global warming, the UN, the UN Framework Convention, the Kyoto Protocol, the Paris Agreement, the 26 ${ }^{\text {th }}$ UN Conference on Climate Change, P. A. Sorokin, integralism.

\section{For citation}

Zolkhoeva M. V. Threat of Global Warming: A Moral Dimension (from the perspective of the Philosophy of Integralism). Bulletin of Buryat State University. Philosophy. 2021; 4: 3-10.

The article was submitted 11.11.2021; approved after reviewing 15.11.2021; accepted for publication 15.11.2021. 